\title{
Contour Crafting Technology: The Toothpaste for Constructions
}

\author{
Andrea Palazzo*1, Daniel Macek ${ }^{2}$ \\ ${ }^{1}$ Department of Construction Management and Economics, Faculty of Civil Engineering, CTU, \\ Thákurova 7, Prague, 166 29, Czech Republic, andrea.palazzo@fsv.cvut.cz \\ ${ }^{2}$ Department of Construction Management and Economics, Faculty of Civil Engineering, CTU, \\ Thákurova 7, Prague, 166 29, Czech Republic, daniel.macek@fsv.cvut.cz
}

\begin{abstract}
The raw concrete material, that influenced architecture in the 1950's is back. The comeback can be found in the building automation called Contour crafting. This 3D printing technology is a new challenge in the world of construction for architects, engineers and building company. The enormous advantages in terms of design, low-cost production, low-waste materials and fast execution make this new generation of buildings one of the greatest interesting technology for the future. Contour crafting is useful in a wide range of circumstances, from counter the disproportionate increase in the prices of ordinary construction and limited availability of manpower -applying it in case of future pandemics like the one we recently experienced- to being used by NASA for projects on other planets. The article will help to better understand the development of this technology in the coming years and will be used by the author for further insights.
\end{abstract}

\section{Keywords}

Additive manufacturing; contour crafting; printing technology; raw concrete; 3D-printing

\section{JEL Classification}

R31 Housing Supply and Markets

O32 Management of Technological Innovation and R\&D

DOI: https://doi.org/10.14311/bit.2021.02.05

Editorial information: journal Business \& IT, ISSN 2570-7434, CreativeCommons license (c) () published by CTU in Prague, 2021, http://bit.fsv.cvut.cz/ 


\section{Introduction}

The use of concrete in buildings and architecture is certainly not new. The advantages of using this material were already known in Roman times as "betunium".

Used in many sectors, even in shipyards back in 1855, over the years concrete has demonstrated specific characteristics for building construction. After several examples in the field of architecture, in the 1950 s this material was extolled by Le Corbusier. The use of concrete by this architectural icon that coined the term "béton brut" gave birth to an art movement, brutalism.

This material made it possible to make the "free plan" by getting rid of the load-bearing walls, where the floors no longer have to overlap each other.

In the modern era, concrete has undergone further evolutions, from the use of prestressed concrete components to improve performance and make construction processes faster to being used by mega printers for the construction of 3D houses.

The use of 3D printers makes you lose the principle of the free plan from load-bearing walls, but confirms the strong will to leave the material unfinished after being laid. That is how the new generation of raw concrete begins.

\section{Description}

The 3D printer technology has been adopted in the manufacturing industry for many years. Recently it has been used in the construction industry for rapid and practical production of houses. What is impressive is that the new process with contour crafting is able to construct the external and internal walls as a single unit, contrary to previous use of $3 \mathrm{D}$ printers when only parts to be assembled were created.

Contour crafting technology consists of using robot arms and extrusion nozzles that repeatedly lay down layers allowing it to make any kind of shape. In its initial stages mostly concrete was used, but the advances of the technique now also allow it to use reinforcing fibres, additives and various other materials of mortar-based mixture.

This revolutionary technology can provide significant benefits to the construction industry in terms of:

- building construction costs

- reduction of construction time

- reduction of construction waste

- reduction of the number of people involved on spot

- reduction of $\mathrm{CO}_{2}$ emissions 
Figure 1: Traditional construction process vs 3D printing

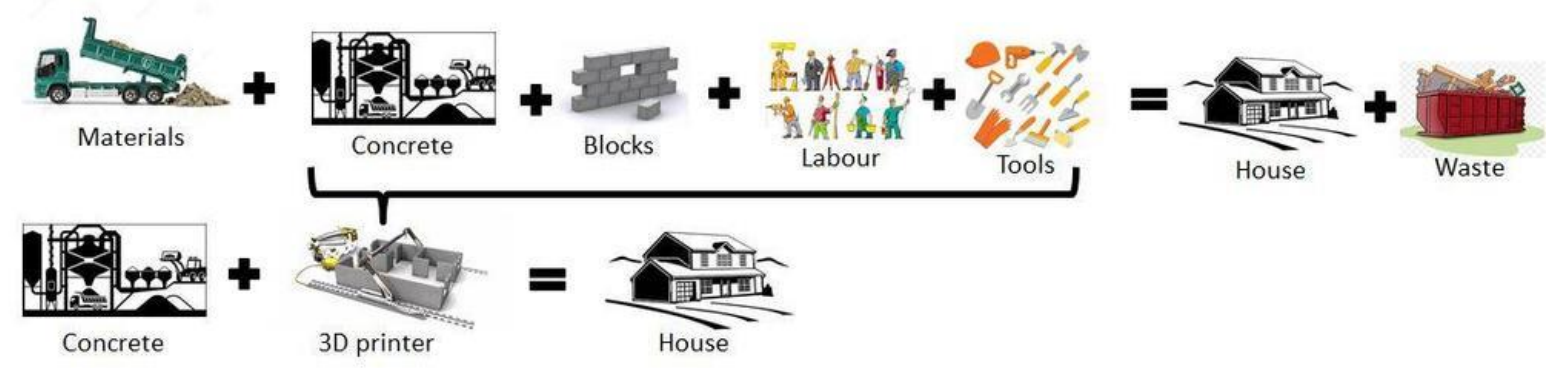

Source: DocPlayer.net

What advantages does it offer to architects and engineers?

- freedom in architectural and structural design

- unlimited possibilities to implement geometric complexity

What are the benefits for the building company?

- Low cost structures and building elements due to high speed of production without moulds or scaffolding

- Productivity $24 / 7$

- New employment possibilities

- Diversification of the technology that can be presented to the client

What are the disadvantages?

- multidisciplinary knowledge concerning material science, architecture/design, engineeringand robotics is requested

- material-mixture formulation

- lack of standard connection between overlapping layers

- only after a wider use will it be possible to evaluate further problems regarding the longevity of these constructions

- reduction of the number of people involved on spot

- type of maintenance still unknown (depends on the area of the installation Africa, North Pole etc.)

- no clear advantage in term of costs

- missing standardisation and certification of printing materials

- high initial investment compared to other production methods

- missing legislation and set of standards 


\section{Machines}

There are two types of 3D concrete printer designs in the market. The Robotic Arm systems and Gantry systems.

The concept of the Gantry Printer is practically identical to the classic overhead crane for containers, the difference being that the print nozzle of the concreate is locate on the beams, which makes it able to move in XYZ Cartesian coordinates exactly as the overhead crane does with the container. For the easy movement of the crane, the flexible hose of the printing material is also connected to the glider system.

Figure 2: Overhead crane vs Gantry Concrete Printer

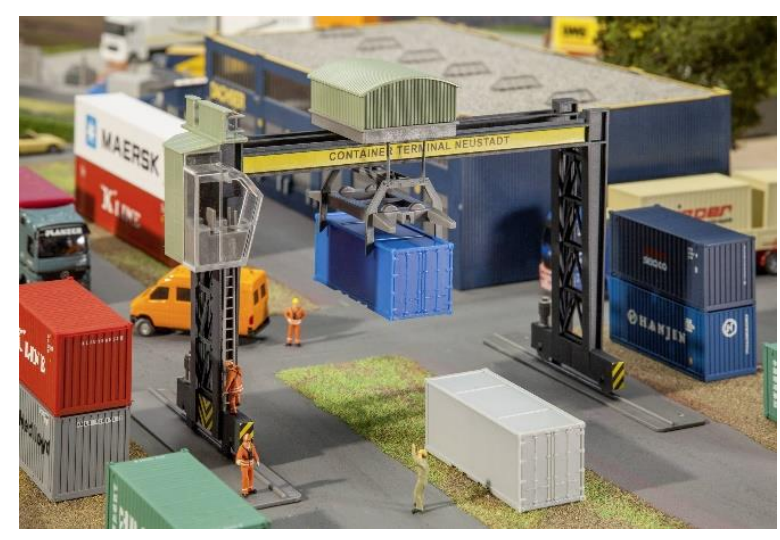

Source: conrad.it

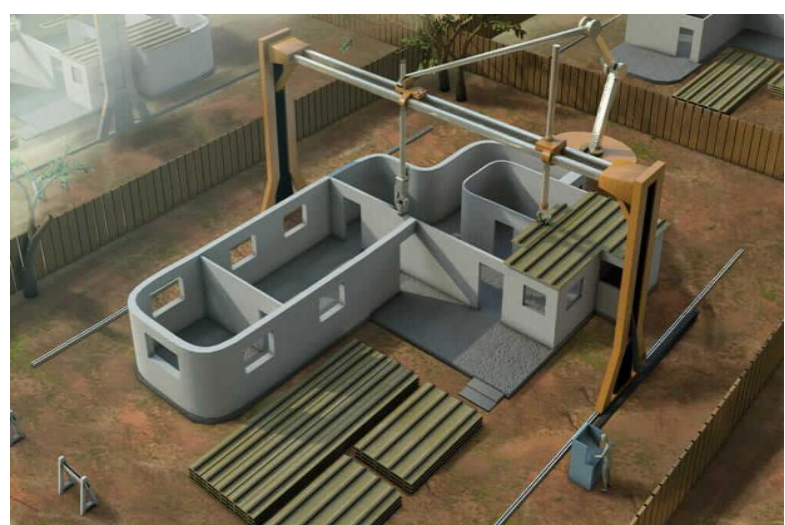

inhabitat.com

The Robotic Arm system, in contrary, is placed on a vertical metal frame which is anchored to the ground, similar to what we can find in a classic crane for construction. In the end of the telescopic arm that applies the concrete layer by layer is located the nozzle.

Figure 3: Construction crane vs Robotic Arm system
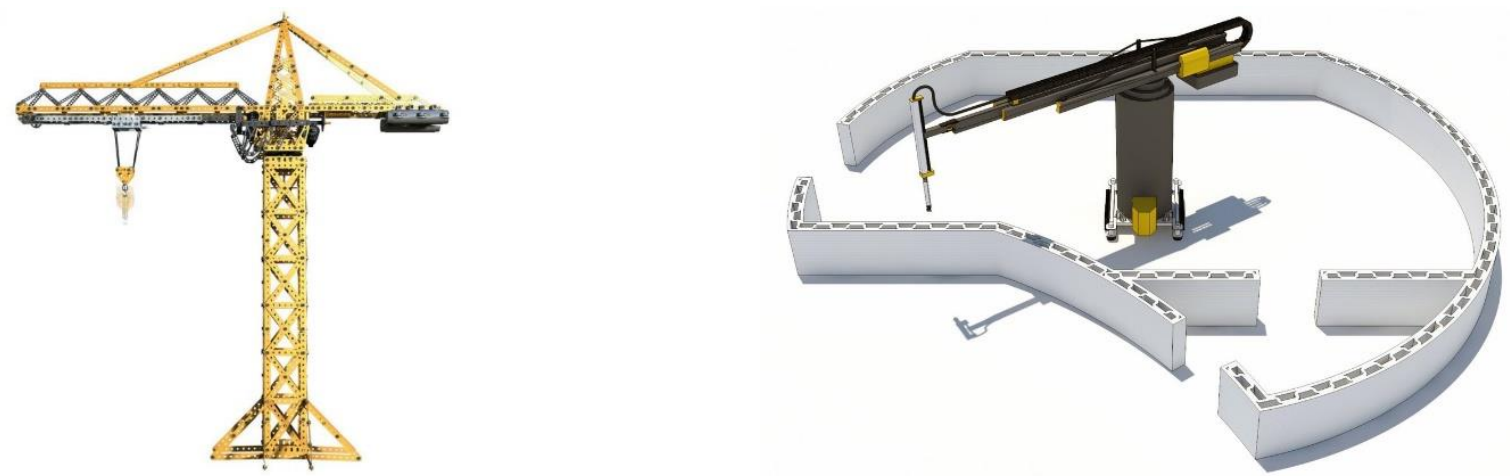
The Robotic Arms printer is smaller than the Gantry printer, giving it an advantage as far as mobility is concerned. The Robotic Arm gives the possibility to print any shape, an element that Gantry printers would have a difficulty doing as they use only three 3- axis movement, but at the same time Gantry printers allow you to make larger prints, a limit that Robot Arms have depending on the size of the arm which can reach specific lengths.

\section{International Developments and Challenges}

The samples that we present are the most interesting projects realized. This collection of developments gives a perfect idea about how technology has been improving, and how the size and the shape are changing really fast in the last years. The bigger printers the company is able to produce, the bigger houses we will be able to see in the market.

\section{Apis Cor}

Figure 4: From the tiny house of $38 \mathrm{~m}^{2}$ in Russia in 2017 to the world's biggest printed building in 2019 in Dubai $\left(640 \mathrm{~m}^{2}\right)$
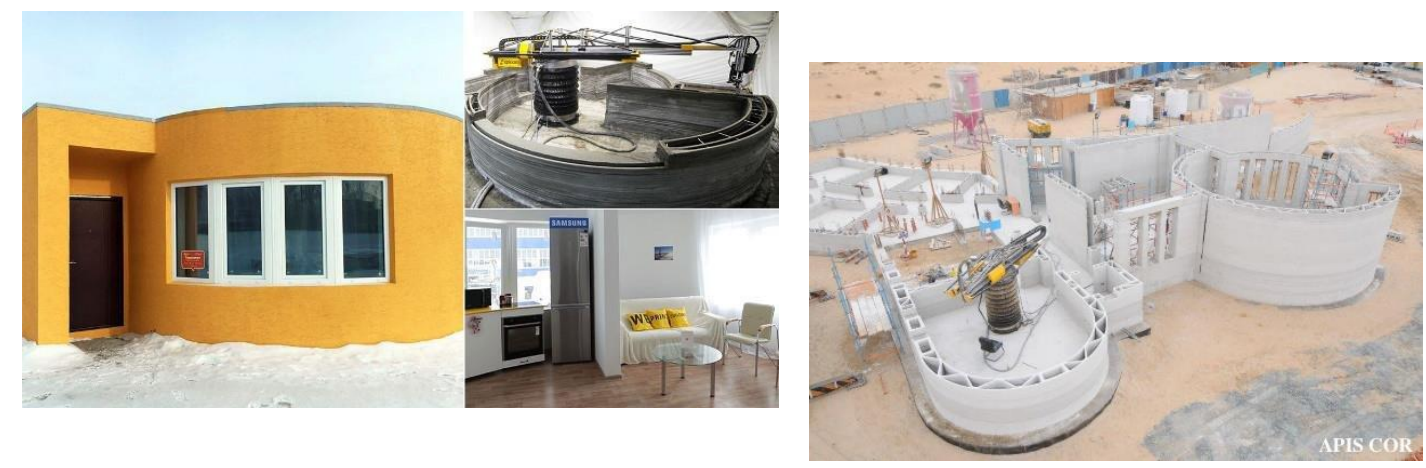

Source: Apis Cor

WinSun Global

Figure 5: The world's first 3D-printed commercial building in Dubai

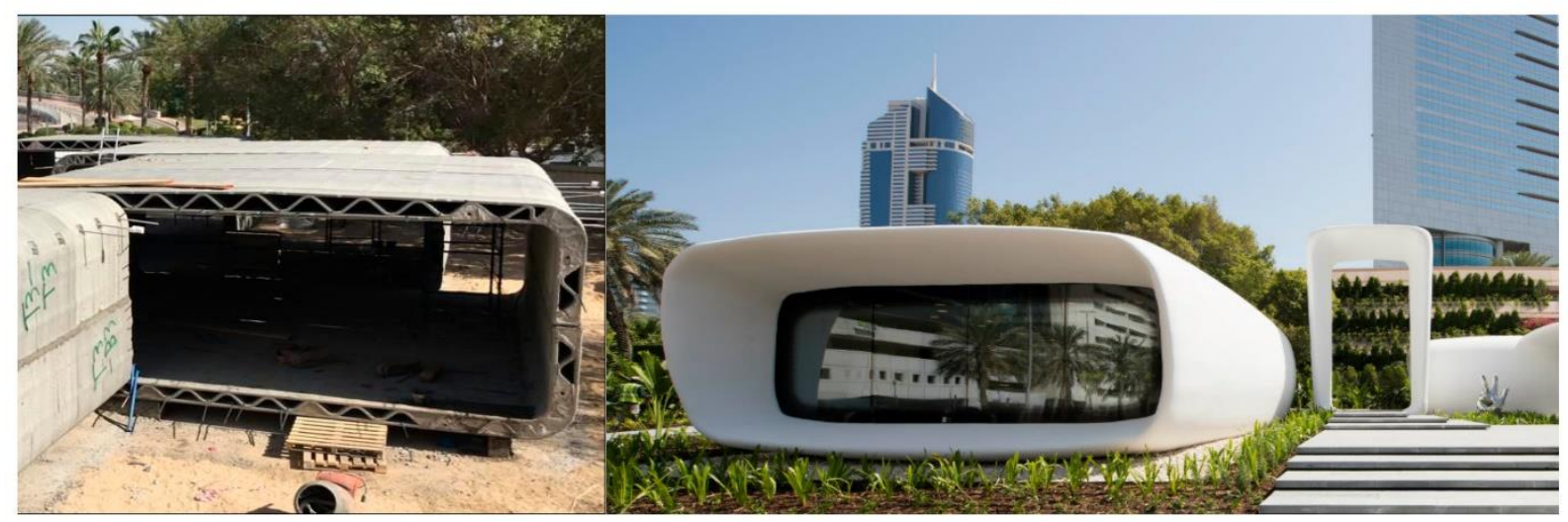

Source: WinSun 


\section{New story and ICON}

Figure 6: Texas development concept
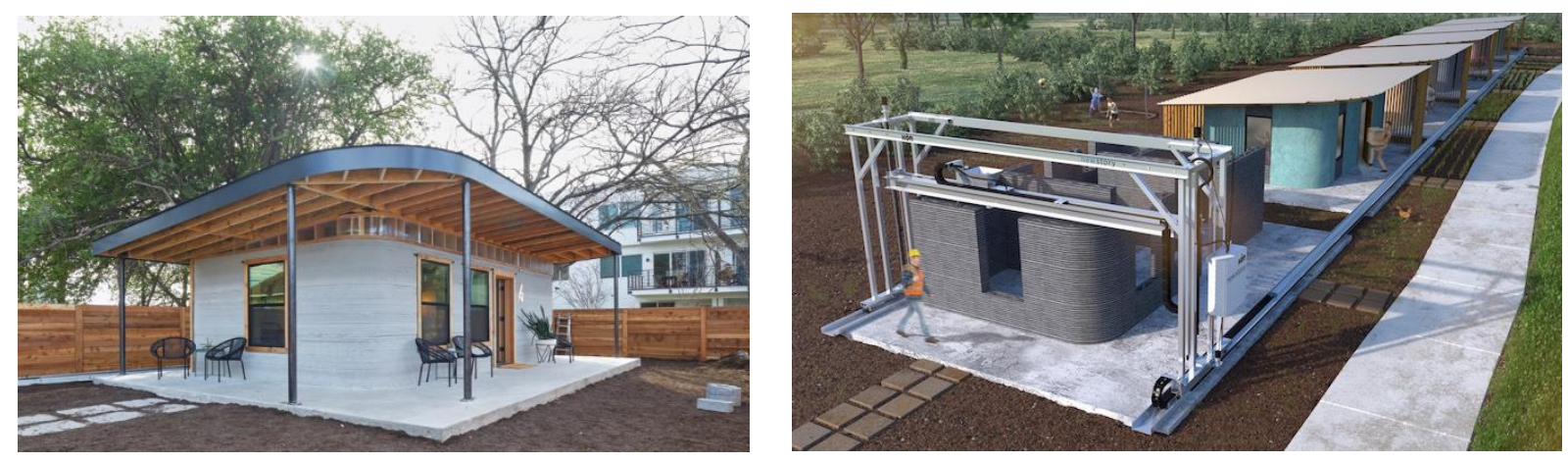

Source: themanufacturer.com

\section{Michal Trpak}

Figure 7: The world's first 3D-printed floating house (Czech Republic)


Source: Bydleni raz dva

czechcrunch fotoScoolpt

\section{WASP Italia}

Project TECLA (Mario Cuccinella Architect) and Project GAIA

3D printed Eco Building using:

- $25 \%$ of soil taken from the site ( $30 \%$ clay, $40 \%$ silt and $30 \%$ sand)

- $40 \%$ from straw chopped rice

- $25 \%$ rice husk

- $10 \%$ hydraulic lime 
Figure 8: Project TECLA (Mario Cuccinella Architect) and Project GAIA

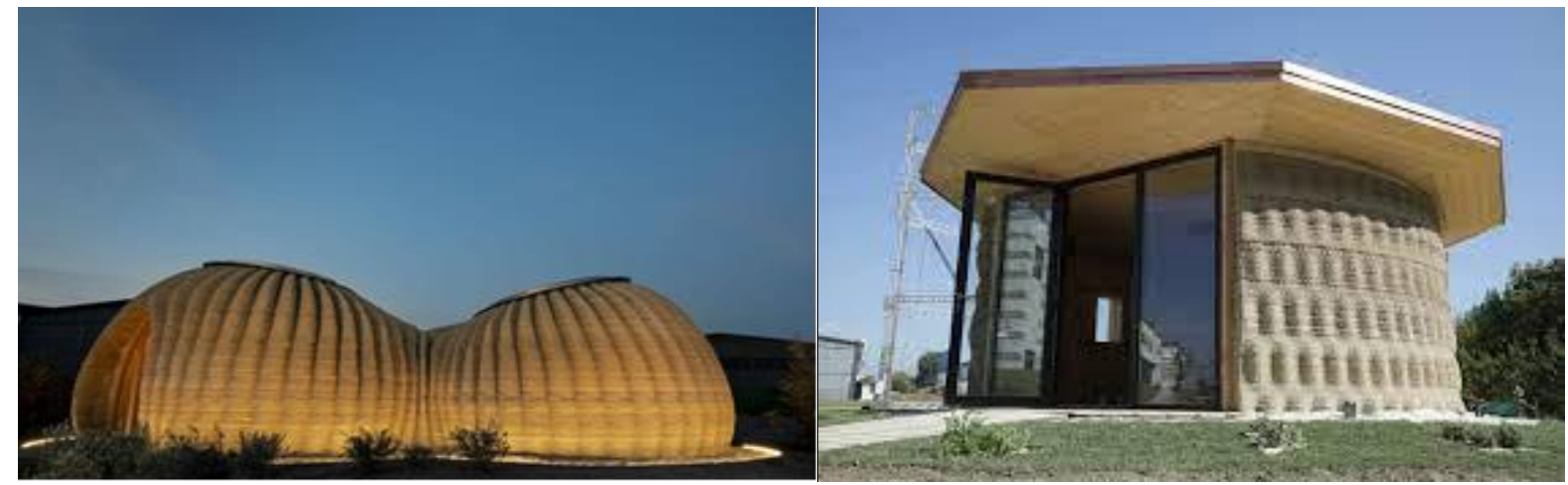

Source: the architect newspaper

3dwasp web side

Milestone Project, Eindhoven University of Technology and Vesteda housing corporation

Figure 9: The Europe's first inhabited 3D-printed house
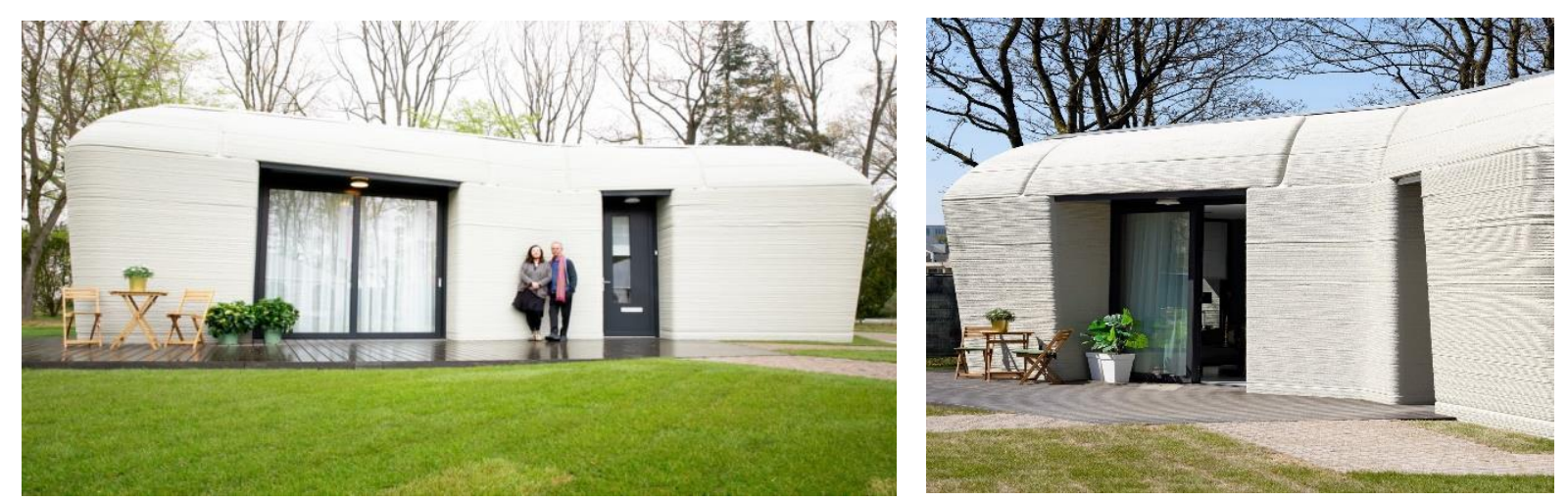

Source: theguardian.com

PERI and COBOD's German distribution partner

Figure 10: The Germany's First 3D-Printed Residential Building

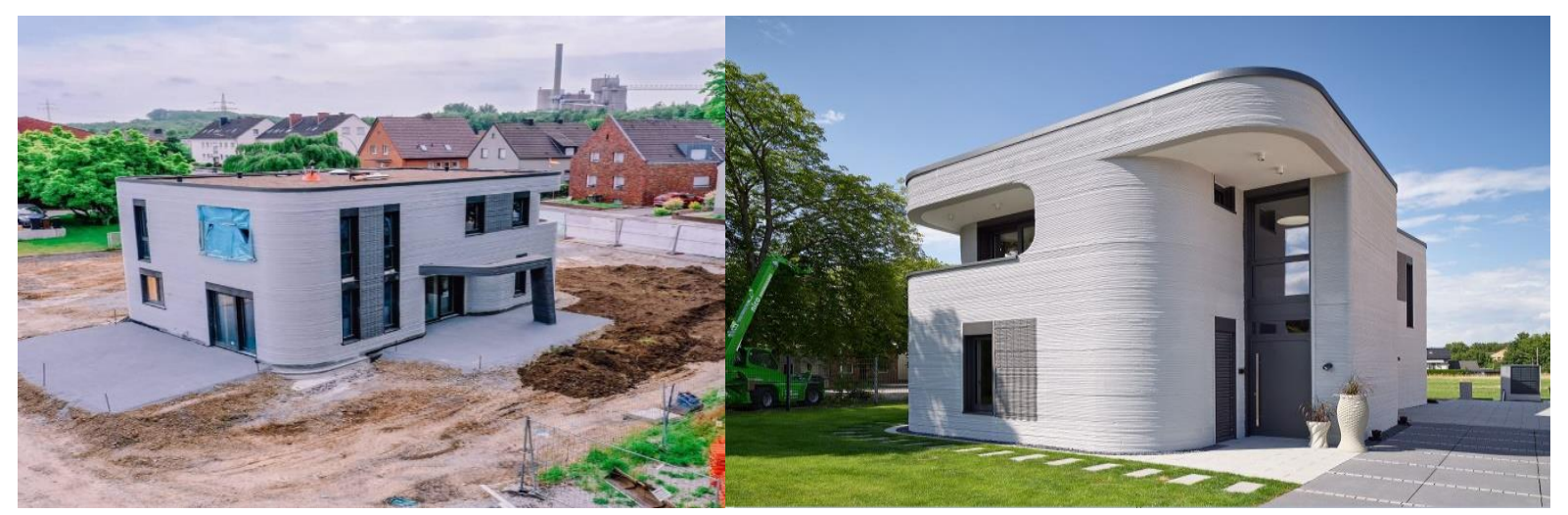

Source: interestingengineering.com 


\section{SQ4D INC.}

Figure 11: Home model prototype (left) and the First Legally Permitted 3D Printed House in the USA for sale online through Zillow (right)

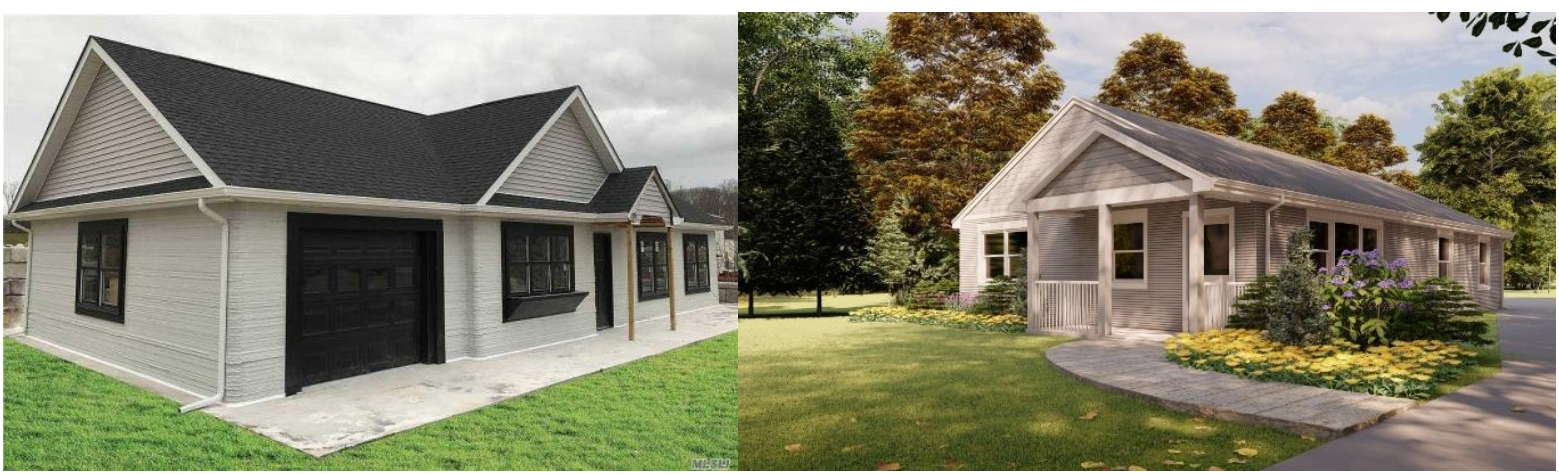

sq4d.com

\section{Conclusion and Recommendations}

As time progresses, we predict more and more companies will develop the construction of 3D printed buildings even more. This, combined with the ever-advancing technologies, should bring prices down and quality up.

The study has shown that even thought, many companies follow a different approach, they are still able to produce a product that respects the main point of this technology, fast execution and cheap price.

The cost of printing a tiny home to $3 D$ is as low as $€ 10,000$. Prices vary greatly according to the materials being used and the size of the home to be 3D printed.

In the Czech Republic there are two companies using this technology, PERI and DEK. At the moment, DEK in partnership with CVUT cathedra of technology construction (Technologhie staveb) with Prof. Usmanov are doing specific research in this field.

$3 \mathrm{D}$ concrete technology is a promising technique that can bring huge changes in the construction industry, but the road to immortality is still uphill. We will see in the future how it will develop and how it will be able to hook a greater number of customers and companies.

Every new innovation comes with a price that tends to go down over time. Large concrete 3D printer's constructions are no exception. Therefore, we will continue to follow these developments carefully for future studies.

\section{References}

[1] Ortega G.S., Madrid J.A., Nils O. E. Olsson and Tenorio Ríos J.A.The Application of 3D-Printing Techniques in the Manufacturing of Cement-Based Construction Products and Experiences Based on the Assessment of Such Products PDF Available online at: https://www.researchgate.net/publication/343758087 The Application of 3DPrinting Techniques in the Manufacturing of Cement- 
Based Construction Products and Experiences Based on the Assessment of Such Produc $\underline{\text { ts }}$

[2] Béton brut, avaible on line at : https://en.wikipedia.org/wiki/B\%C3\%A9ton brut

[3] Yeşim Tarhan DEVELOPMENTS OF 3D CONCRETE PRINTING PROCESS https://www.researchgate.net/profile/Yesim-Tarhan

[4] Caula R. Chinese company 3D prints 10 recycled concrete houses in 24 hours. Available online at: https://www.designboom.com/technology/3d-printed-houses-in-24-hours-04-24-2014/

[5] Angelopoulou S.L. First permitted 3D-printed house by SQ4D hits the market in the US. Available online at: https://www.designboom.com/architecture/first-permitted-3d-printed-house-sq4dhits-the-market-us-02-18-2021/

[6] Olick D. You can now buy a 3D-printed home - here's a look inside. Available online at: https://www.cnbc.com/2021/02/25/you-can-now-buy-a-3d-printed-home-heres-a-lookinside.html

[7] Real estate Zillow offer. Available online at: https://www.zillow.com/homes/34-millbrook-Inriverhead,-ny,-11901 rb/2075583035 zpid/

[8] By editorial board. Case Stampate in 3D ormai una realtà. Quanto costano e come vengono costruite. Available online at: https://www.stampa3dstore.com/case-stampate-in-3d-ormaiuna-realta-quanto-costano-e-come-vengono-costruite/

[9] Gregurić L. How Much Does a 3D Printed House Cost in 2021? Available online at: https://all3dp.com/2/3d-printed-house-cost/

[10] Widner C. The tiny 3D-printed home at SXSW is adorable. Available online at: https://austin.curbed.com/2018/3/14/17116504/tiny-home-austin-sxsw-3d-printed-affordable

[11] By editorial board. 3D Printed House - Design \& Build It Yourself. Available online at: https://www.3darchitect.co.uk/3d-printed-house

[12] By editorial board. Office of the Future / Killa Design. Available online at: https://www.archdaily.com/875642/office-of-the-future-killa-design

[13] Block I. World's largest 3D-printed building completes in Dubai. Available online at: https://www.dezeen.com/2019/12/22/apis-cor-worlds-largest-3d-printed-building-dubai/

[14] Czech sculptor creates 3D-printed floating house to be displayed in Prague. Available online at: https://kafkadesk.org/2020/06/18/czech-sculptor-creates-3d-printed-floating-house-to-bedisplayed-in-prague/ 